\title{
The glutamate analogue quisqualic acid is neurotoxic in striatum and hippocampus of immature rat brain
}

\author{
Faye S. Silverstein ${ }^{1}$, Ronni Chen ${ }^{1}$ and Michael V. Johnston ${ }^{1,2}$ \\ 'Departments of Pediatrics and Neurology, University of Michigan Medical School, and ${ }^{2}$ Center for Human \\ Growth and Development, University of Michigan, Ann Arbor, MI (U.S.A.)
}

(Received 28 May 1986; Revised version received and accepted 7 July 1986)

Key words: Quisqualate - Neurotoxic - Immature brain - Striatum - Hippocampus - Rat

To assess the neurotoxic properties of the glutamate agonist quisqualic acid (QA) in immature brain, we injected this compound $(100 \mathrm{nmol} Q A / 1 \mu \mathrm{l})$ directly into the striatum of 7-day-old rats. QA produced neuronal necrosis and glial infiltration in 14 pups and reduced the size of the striatum and hippocampus on the side of injection. Intracerebral injection of QA provides a new method for producing neuronal lesions in the developing brain.

Multiple excitatory amino acid receptor subtypes have been identified in mammalian brain [13]. N-methyl-D-aspartate (NMDA)-, quisqualic acid (QA)-, and kainic acid (KA)-preferring glutamate receptors have been distinguished both by biochemical and electrophysiologic criteria. The immature brain is relatively resistant to neuronal damage from KA, a conformationally restricted glutamate analogue with convulsant and neurotoxic properties in adult animals [2]. Development of susceptibility to excitotoxic lesions from KA with maturity has been correlated with the expression of presynaptic markers for corticostriatal glutamate pathways. However, the immature brain, both in rats and human infants, contains high concentrations of postsynaptic glutamate receptors in the corpus striatum, globus pallidus and hippocampus. Moreover, in the globus pallidus, which has virtually no glutamate receptors in adults, there is a high density of glutamate receptors in 7-day-old rats; these receptors disappear over the next two postnatal weeks [5]. In the corpus striatum, glutamate receptors reach adult levels by day 7 although the presynaptic glutamate uptake process lags behind. In contrast to the adult striatum, which is enriched in NMDA receptors, [4], preliminary studies have demonstrated that the immature striatum contains a large proportion of QA-preferring glutamate receptors (J.T. Greenamyre, personal

Correspondence: F.S. Silverstein, Neuroscience Laboratory Building, 1103 E. Huron, Ann Arbor, MI 48104, U.S.A. 
communication). This observation suggested that glutamate agonists which stimulate QA receptors might be most potent neurotoxins in the immature brain. In this study, we report that direct intracerebral injection of QA causes neuronal destruction in the basal ganglia and hippocampus of 7-day-old rats.

Seven-day-old Sprague-Dawley rats were used for these experiments. Pups were briefly anesthetized with ether, positioned in plaster of Paris molds, and placed in a stereotaxic apparatus (David Kopf). Coordinates for intrastriatal injection were determined initially using surface anatomic landmarks, injecting $1 \mu \mathrm{l}$ of copper sul-

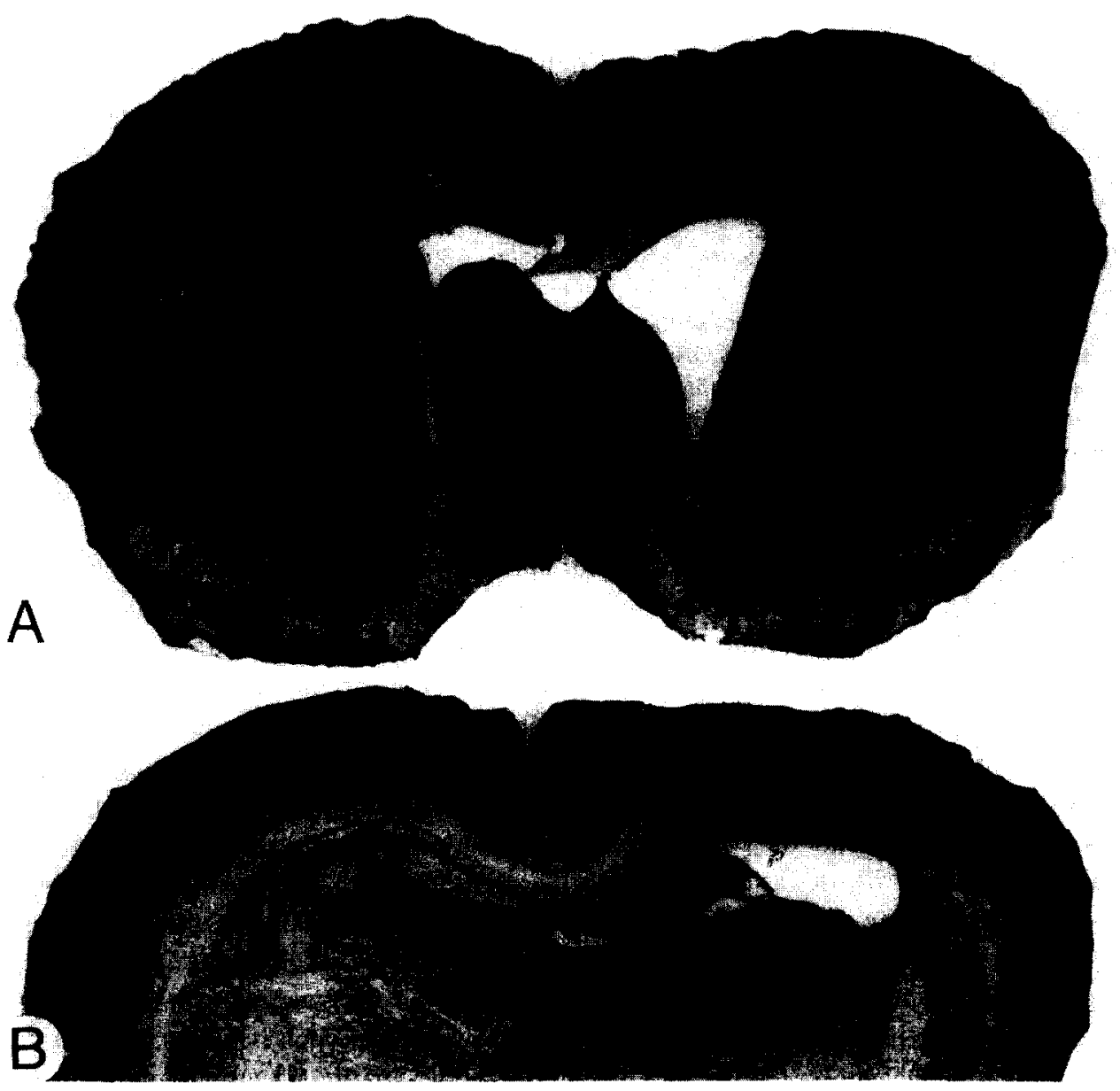

Fig. 1. A: Nissl-stained coronal section of rat brain at the level of the striatum. On day 7 the animal received a $1-\mu l$ intrastriatal injection of $0.1 \mu \mathrm{mol}$ of QA dissolved in $0.01 \mathrm{M}$ Tris, $\mathrm{pH} 7.4$. The pup was killed on day 12 . The size of the striatum is reduced unilaterally and there is an asymmetric enlargement of the lateral ventricle. Within the striatum, along the needle track, the cellular organization is disrupted. This unilateral striatal lesion was present in all 14 pups that received QA and in nonc of the Tris-injected controls. B: a more posterior section demonstrates a unilateral hippocampal lesion (details in Fig. 2). S, septum: $\mathrm{C}$, caudate; $\mathrm{H}$, hippocampus. 
fate solution with a Hamilton syringe, and identifying the location of tissue damage. QA (Sigma) was dissolved in $0.01 \mathrm{M}$ Tris, $\mathrm{pH} 7.4$ (final concn., $0.1 \mathrm{M}$ ); $1 \mu \mathrm{l}(100$ $\mathrm{nmol} / \mu \mathrm{l})$ was injected into the striatum over $5 \mathrm{~min}(n=14)$. In age-matched controls, $1 \mu \mathrm{l}$ of diluent was injected $(n=4)$. All pups were returned to the dam for 5 days and on day 12 , they were decapitated, the brains were removed, placed into phosphatebuffered formalin, and then $50-\mu \mathrm{m}$ frozen sections were stained with Cresyl violet. Cross-sectional areas of the striatum and hippocampus were determined by outlining enlarged images of histologic sections projected on tracing paper, weighing cut-outs of the striatum and hippocampus, and comparing their weights with those of cut-outs of known cross-sectional area.

Hypoxic neuronal damage may be mediated by excitatory neurotransmitter release [9]. To determine if hypoxic exposure could potentiate the deleterious effects of QA in one of the experiments, 5 animals received QA injections alone and 5 litter-mates were exposed to an $8 \%$ oxygen $\left(\mathrm{O}_{2}\right)$, balanced nitrogen environment for $1.5 \mathrm{~h}$ after the injection of QA. Normal rat pups tolerate $8 \% \mathrm{O}_{2}$ exposure well for many hours. While 2/5 QA-injected pups exhibited mild contralateral turning in room air, exposure to moderate hypoxia markedly enhanced this response. All rats placed in $8 \% \mathrm{O}_{2}$ after QA injections twisted and turned markedly to the left and after $1.5 \mathrm{~h}$ of hypoxia appeared ill.

A consistent pathologic lesion was found in all pups which received QA (Fig. 1). The size of the corpus striatum was reduced on the side of the injection and there was a corresponding unilateral enlargement of the lateral ventricle. High power microscopic examination of this area demonstrated abnormal cellular organization, neuronal necrosis, and glial infiltration along the needle track and extending into the globus pallidus. Unilateral lesions of the hippocampus were observed as well (Figs. $1 \mathrm{~B}$ and 2). Areas adjacent to the ventricle were most susceptible to neuronal damage, the pyramidal cell layer of $\mathrm{CA}_{3}$ was disrupted and tissue mass was markedly diminished. Hippocampal lesions were most likely attributable to leaking of drug into the adjacent ventricle; with intrastriatal copper sulfate injections ependymal damage de-
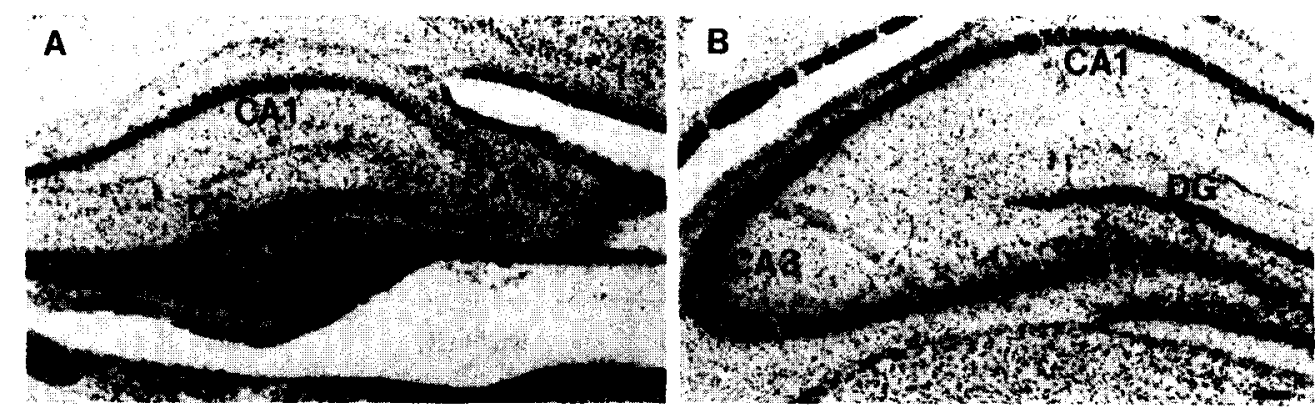

Fig. 2. Photographs of Nissl-stained formalin-fixed sections of hippocampus from a 12-day-old animal. On day 7 the pup received a $1-\mu \mathrm{l}$ intrastriatal injection of $0.1 \mu \mathrm{mol}$ of QA. The pup was killed on day 12. A: on the side of injection, the tissue adjacent to the lateral ventricle is necrotic and the pyramidal cells in regions of $\mathrm{CA}_{3}$ and $\mathrm{CA}_{4}$ are disrupted. $\mathrm{B}$ : the opposite side is intact. $\mathrm{Bar}=100 \mu \mathrm{m}$; CA, cornu ammonis, DG, dentate gyrus. 
veloped in the adjacent ventricle. In contrast, in controls, tissue integrity was preserved, and the ventricular size was equal bilaterally.

In QA-treated animals, measurement of the striatal cross-sectional area demonstrated consistent tissue loss in the striatum $(-8.9 \pm 1.9 \%$ compared with the contralateral striatum; $-17.5 \pm 2.7 \%$ compared with control; $P<0.001$, Student's $t$-test; Table I). In the hippocampus ipsilateral to the injection the cross-sectional area was reduced $(-53 \pm 9.5 \%$ compared with the opposite side; $-71 \pm 7 \%$ compared with control; $P<0.001, t$-test) and the size of the hippocampus contralateral to the injection was also reduced $(-33 \pm 13 \% ; P<0.05$ compared with values in age-matched controls). In the striatum the extent of tissue loss was significantly greater in pups exposed to hypoxia $(-8.9 \pm 1.9 \%$ vs $-22.3 \pm 2.6 \% ; P<0.005, t$-test $)$.

These results demonstrate for the first time that a glutamate agonist, QA, is neurotoxic for the immature basal ganglia and hippocampus. In adult rats, QA is relatively inactive as a neurotoxin in the striatum [14]. QA may be toxic in 7-day-old rats because of the preponderance of the QA receptor sub-type at this age. A recent report [8] suggests an additional molecular mechanism for the differential response to glutamate agonists and perhaps for greater potency of QA in immature brain. Glutamate receptor activation stimulates inositol phospholipid hydrolysis. Inositol phosphate (PI) and diacyl glycerol are released and these compounds trigger intracellular biochemical events, e.g. calcium mobilization and arachidonic acid release, which, in excess, may contribute to irreversible neuronal damage. In vitro, in hippocampal tissue from 7-day-old pups, QA is one of the most potent stimuli of PI turnover. Ibotenate, an NMDA agonist, which is an equally potent activator of PI turnover at this age [8], also elicits neuronal damage in immature brain [12]. In contrast, KA, which is not toxic in vivo at this age does not stimulate PI turnover. Excessive PI turnover may play a role in the pathogenesis of the neuronal damage observed from QA.

Direct intrahippocampal injection of QA in adult cats causes seizures and preferen-

TABLE I

\section{CROSS-SECTIONAL AREA OF STRIATUM}

All animals received $1-\mu$ injections into the right striatum on day 7 . Rat pups were killed on day 12 and formalin-fixed frozen sections were prepared. Areas were derived from weights of tracing paper outlines of enlarged images of histologic sections; in each lesion 7 analogous sections were measured. Values are expressed as mean \pm S.E.M. For statistical analysis, bilateral control values were combined. ${ }^{*} P<0.02$, ${ }^{* *} P<0.001$; comparison with control values using Student's $t$-test.

\begin{tabular}{lllll} 
& $n$ & \multicolumn{2}{l}{ Striatal area $\left(\mathrm{mm}^{2}\right)$} & \\
\cline { 2 - 3 } & & Left (L) & Right (R) & $\Delta \%(\mathrm{l}-\mathrm{R} / \mathrm{L})$ \\
\hline Control & 4 & $5.42 \pm 0.04$ & $5.27 \pm 0.11$ & $+1.4 \pm 2.2$ \\
Quisqualate & $6^{\mathrm{a}}$ & $4.79 \pm 0.09^{* *}$ & $4.36 \pm 0.14^{* *}$ & $-8.9 \pm 1.9^{*}$ \\
Quisqualate & 7 & $4.91 \pm 0.13^{*}$ & $3.80 \pm 0.12^{* *}$ & $-22.3 \pm 2.6^{* *}$ \\
$+1.5 \mathrm{~h}$ of $8 \% \mathrm{O}$ & & & & \\
\hline
\end{tabular}

"In a seventh animal, the lesion was present but there were too few sections for quantitation. 
tial damage to pyramidal cells of $\mathrm{CA}_{3}$ [3]. Since electroencephalograms were not done in this study we cannot assess if seizures had a role in the pathogenesis of neuronal damage. However, with other glutamate analogues, there is a poor correlation between neurotoxic potency and epileptogenic action and excessive excitation is not a sufficient explanation for neuronal degeneration [14].

Hypoxia increased tissue damage from QA. In dispersed fetal hippocampal cells in culture, excitatory amino acid neurotransmitters mediate hypoxic cell death [9]. Excessive stimulation of glutamate receptors may play a critical role in selective neuronal vulnerability to a variety of metabolic insults including hypoxia-ischemia, status epilepticus and hypoglycemia [7]. In 7-day-old rats, unilateral carotid artery ligation followed by $1.5 \mathrm{~h}$ of $8 \% \mathrm{O}_{2}$ exposure produces focal neuronal damage in forebrain ipsilateral to ligation. In this well-characterized small animal model of perinatal hypoxic-ischemic brain injury, glutamatergic synaptic function is disrupted: presynaptic glutamate uptake is markedly inhibited [10] and there are selective reductions in density of postsynaptic glutamate receptors [11]. In adult animal models of ischemic brain injury, stimulation of glutamate release with ischemia has been observed using microdialysis [1]. Although such measurements have not yet been done in immature animals, excessive glutamate release may also play a role in the pathogenesis of hypoxic-ischemic brain injury at this age. It is noteworthy that the histopathologic appearance of the QA lesions closely resembles the lesions resulting from carotid ligation and hypoxic exposure [6]. Use of intracerebral QA injections provides a new method for producing neuronal lesions in the developing brain.

Our observations suggest that excessive release of endogenous glutamate or analogous substances could produce neuronal destruction in the immature brain. The data support the hypothesis that this mechanism may contribute to the evolution of brain damage from perinatal asphyxia. We speculate that certain regions in the developing brain such as the caudate-putamen, globus pallidus and hippocampus, may be targeted for hypoxic-ischemic damage because they contain high concentrations of specific 'QA-preferring' glutamate receptors.

We thank J.T. Greenamyre for helpful discussions. This work was supported by PHS Grants NS 00603 and NS 17642 (M.V.J.), Grant 326 from the United Cerebral Palsy Research and Education Foundation (M.V.J.) and a fellowship from the Medical Research Council of Canada (F.S.S.)

1 Benveniste, H., Drejer, J., Schousboe, A. and Diemer, N.H., Elevation of the extracellular concentrations of glutamate and aspartate in rat hippocampus during transient cerebral ischemia monitored by intracerebral microdialysis, J. Neurochem., 43 (1984) 1369-1374.

2 Campochiaro, P. and Coyle, J.T., Ontogenetic development of kainate neurotoxicity: correlates with glutamatergic innervation, Proc. Natl. Acad. Sci. USA, 75 (1978) 2025-2029.

3 Fukada, H., Tanaka, T., Kadima, M., Nakai, H. and Yonemasu, Y., Quisqualic acid-induced hippocampal seizures in unanesthetized cats, Neurosci. Lett., 59 (1985) 53-59.

4 Greenamyre, J.T., Olson, J.M., Penney, J. and Young, A.B., Autoradiographic characterization of Nmethyl-D-aspartate-, quisqualate- and kainate-sensitive glutamate binding sites, J. Pharmacol. Exp. Ther., 233 (1985) $254-263$. 
5 Greenamyre, J.T., Penney, J.B., Silverstein, F., Johnston, M.V. and Young, A.B., A transient dense. post-natal expression of glutamate binding sites in globus pallidus, Soc. Neurosci. Abstr., 10 (1984) 225.

6 Johnston. M.V.. Neurotransmitter alterations in a model of perinatal, hypoxic-ischemic brain injury. Ann. Neurol., 13 (1983) 511-518.

7 Meldrum, B., Excitatory amino acids and anoxic ischemic brain damage, Trends Neurosci.. 8 (1985) 2: 4748 .

8 Nicoletti, F., Iadorula, M.J., Wroblewski, J.T. and Costa, E., Excitatory amino acid recognition sites coupled with inositol phospholipid metabolism. Developmental changes and interaction with $\alpha_{1}$-adrenoreceptors, Proc. Natl. Acad. Sci. USA, 83 (1986) 1931-1935.

9 Rothman, S., Synaptic release of excitatory amino acid neurotransmitter mediates anoxic neuronal death, J. Neurosci., 4 (1984) 1884-1891.

10 Silverstein, F.S., Buchanan, K. and Johnston, M.V., Hypoxia-ischemia disrupts striatal high affinity ${ }^{3} \mathrm{H}$-glutamate uptake into synaptosomes, J. Neurochem., in press.

11 Silverstein, F.S., Torke, L., Adelman, W. and Johnston, M.V., Perinatal cerebral ischemia disrupts glutamate receptors (abstract), Pediatr. Res., 20 (1986) 4, part 2: 467A.

12 Stciner, H.X.. McBean. G.J., Kohler, C., Roberts. P.J. and Schwarcz, R., Ibotenate-induced neuronal degeneration in immature rat brain, Brain Res., 307 (1984) 117-124.

13 Watkins, J.C. and Evans, R.H., Excitatory amino acid transmitters, Annu. Rev. Pharmacol. Toxicol., 21 (1981) 165-204.

14 Zaczek, R. and Coyle, J.T., Excitatory amino acid analogues: neurotoxicity and seizures, Neuropharmacology, 21 (1982) $15-26$. 